www.conferenceie.ase.ro

\title{
THE IMPACT OF INFORMATION TECHNOLOGY ON ENTREPRENEURSHIP
}

\author{
Amalia FURDUI \\ University of Petroșani, Department of Management and Industrial Engineering \\ iulia_amalia@yahoo.com \\ Eduard-Victor EDELHAUSER \\ University of Petroșani, Department of Management and Industrial Engineering \\ edi1ro2001@yahoo.com \\ Elena-Izabela POPA \\ University of Petroșani, Department of Management and Industrial Engineering \\ izapopa1974@yahoo.com
}

\begin{abstract}
This study aims to identify the importance of enterprises in information technology and the interest of young people for entrepreneurial initiatives in relation to IT enterprises. The data were collected using questionnaires from young people, future graduates, to obtain an image of their intention, motivation and ability to enter into entrepreneurial projects related to IT. The Global Entrepreneurship Monitor report was used to identify entrepreneurial factors. It is noticeable that young people are motivated to set up businesses even at a small level and therefore large and small businesses can play a vital role in assisting and encouraging the entrepreneurial activity of young people with a particular focus on IT businesses. The limitation of this research could be the fact that the data were collected from young people with a higher intellectual level, so that their sense of understanding of entrepreneurial initiatives is better than the level of the students having a lower education. Also, the results might be different if the same research were applied in countries with different demographics. As far as practical implementation is concerned, research can envisage the entrepreneurial spirit among young people and design policies in the opening of new horizons.
\end{abstract}

Keywords: entrepreneurship, information technology, innovation.

JEL classification: A13, L26, M15.

DOI: $10.24818 / \mathrm{ie} 2020.02 .08$

\section{Introduction}

In our age, a support for declining economies is represented by information technology, which is why diversification and advancement in the field of information technology (IT) indicates a huge research topic and entrepreneurship is the main engine by which new knowledge and technologies are transformed into economic benefits and social for European countries. The success and competitiveness of a company is largely determined by the quality of the management and especially by the organization, decisive, informational and not least by the methodological and methodological subsystems. [1]

The European Union (EU) policy in the field of entrepreneurship constantly highlights the need to create the most appropriate micro-and macro-environments to support the development of small and medium-sized companies and entrepreneurship. [2]

Digital entrepreneurship is a new feature of European policies for employment and growth. As the European Commission has stated, new companies and SMEs are major sources of jobs in Europe. According to the Entrepreneurship Indicators Program (EIP), digital entrepreneurship can be divided into: digital entrepreneurs who are individuals and try to generate value by identifying and exploiting new technologies, products, processes and appropriate markets and 
digital entrepreneurial activity it is the enterprising human action in the pursuit of value generation, through the creation and expansion of economic activity, through the identification and exploitation of new products. [3]

The objectives of this research are to investigate the entrepreneurial, technological and innovation intention, to determine the importance of IT enterprises among young people, to analyze the attitudes and perceptions, motivation and aspirations of young people when starting a business.

In order to achieve the research objectives, during the period January - March 2019, the data extracted from 159 questionnaires were answered and answered by young people, students of the 11th and 12th grade from 20 technological high schools in Romania.

In this paper we used data from the Global Entrepreneurship Monitor (GEM) reports and our own data collected using from the questionnaires completed by young people from 20 technological high schools, from Romania. We also used data samples from Europe to analyze how modern youth value entrepreneurship and perceptions of IT-based business.

\section{Theoretical aspects regarding entrepreneurship}

Over the centuries, several studies and theories on entrepreneurship have emerged. The most well-known study in the world of entrepreneurial activity at the moment is the Global Entrepreneurship Monitor (GEM). Started in 1999 as a joint project between Babson College (USA) and London Business School (UK), GEM is the world's richest information resource on entrepreneurship, publishing a number of annual reports at global and national levels. The latest data on the entrepreneurial activity in Romania compared to that of other countries can be found in the GEM Report 2015/2016. The indicators used in the entrepreneurial behavior are: financial support, government policies, governmental entrepreneurial programs, entrepreneurial education, transfer of research and development, degree opening of the internal market, access to physical infrastructure, cultural and social norms.

Figure 1 shows the entrepreneurial activity determined by social values and individual attributes creating an added value of jobs, as well as the social, cultural, political and economic context that influences this activity. GEM also evaluates the specific conditions of entrepreneurship for a company that is trying to start a new action, where it will be supported. Individually and collectively, these conditions influence how easy or difficult it is to start a new business and then develop that new venture into an established sustainable business. [4]

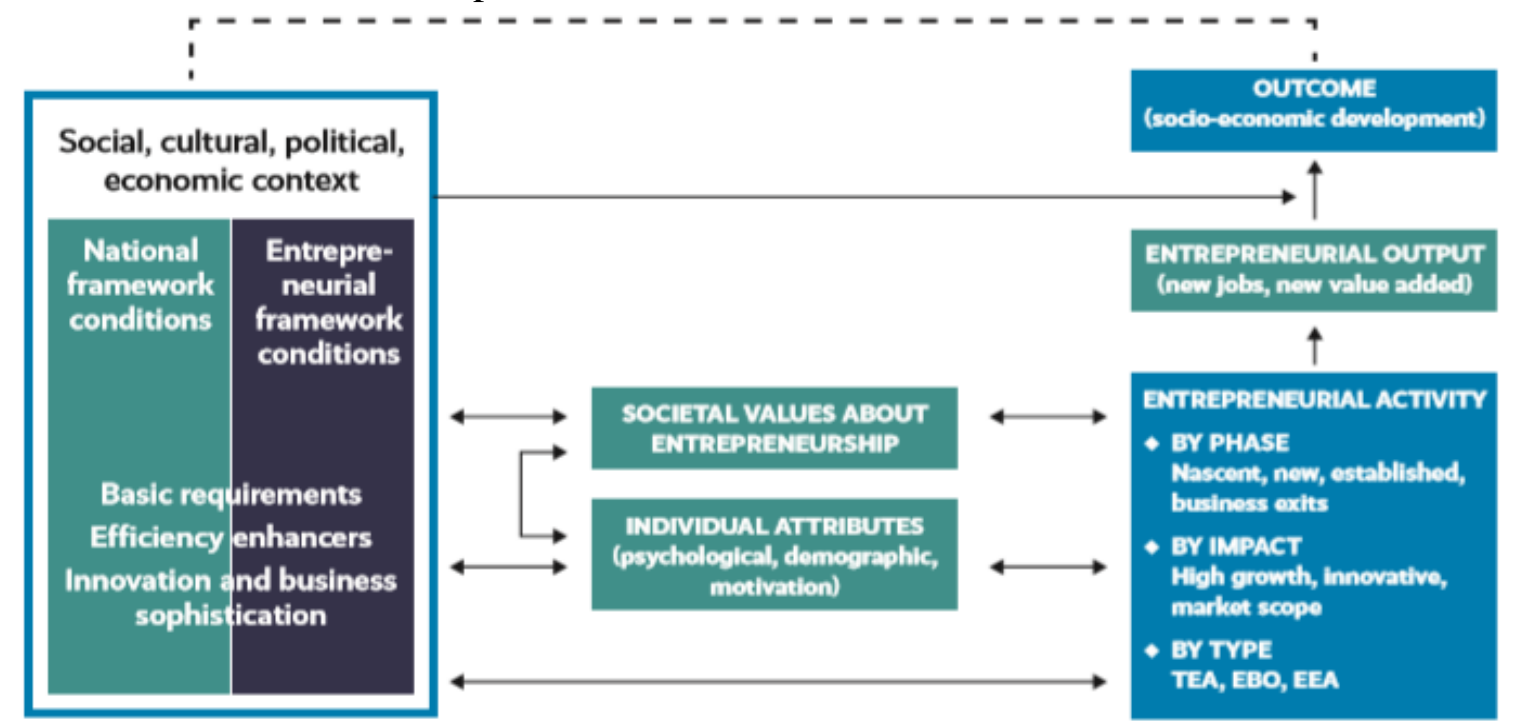

Figure 1. The GEM conceptual frameworks Source: Global Entrepreneurship Monitor 2019/2020 Global Report 
www.conferenceie.ase.ro

The entrepreneurial activity is carried out in the specific context of a given environment, with its own unique social, cultural and economic characteristics when the interaction of perception to the individual about an opportunity and their perceived ability to act on that opportunity in a specific context, gives birth to entrepreneurial activity or business creation and development processes. [5]

Entrepreneurial motivation and entrepreneurial capacity have an effect on economic growth and provides information on the importance of IT businesses in the growth of Gross Domestic Product (GDP), especially in the context of the economies in which they are fluctuating. The entrepreneurial behavior and attitudes in Romania can be seen in figure 2, where Expert Ratings: $1=$ highly insufficient, $9=$ highly sufficient.

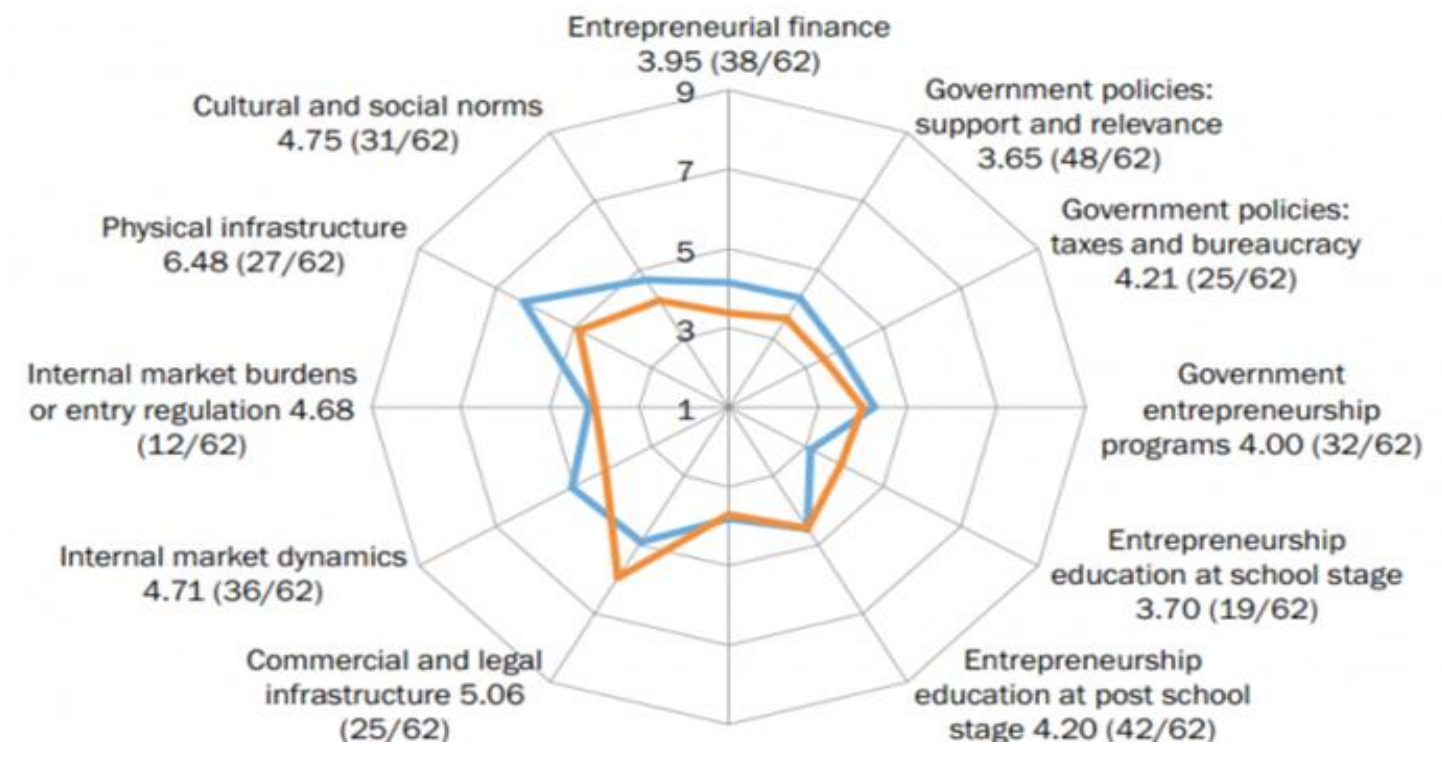

Figure 2- Entrepreneurial Framework Conditions Source: GEM 2015/2016 Global Report

The latest statistical data on Romania appear in the GEM 2015/2016 Global Report, where it can be observed that Romania is between levels 2 and 3 of (Expert Ratings), at that is to say an average level compared to other EU Member States. [4]

In Romania, in 2015, the rate of early-stage entrepreneurial activity (TEA) is $10.8 \%$, being the percentage of the active population who has done something to start a business or already has a company with an age of up to 3.5 years. This specific GEM indicator has a tendency to decrease as the economy grows. Romania is in the middle of the ranking (ranking 30th among the 60 countries that participated in the GEM study 2015/2016). Compared to 2014, Romania registered a slight decrease of 0.5 percentage points, but still exceeds the European average which is $7.8 \%$ or the TEA rate of countries such as Hungary $(7.9 \%)$, Poland (9.2\%) or Bulgaria $(3.5 \%) .[6]$

\section{Research methodology}

The research method used for this study is the questionnaire-based survey. The study is comprehensive and is part of a future doctoral thesis. Criteria contributed to the applied research method: accuracy of results, cost, time of realization, nature of the reference population and sample volume. The advantages that support the efficiency of the chosen method are: facilitating the extraction of the young people subjected to the study, the possibility 
of a rigorous control of the data collection process, a cost and a short time of determining the sample.

The questionnaire used comprises 15 open, closed and even multiple-choice questions and the study is much broader and is part of a future doctoral thesis. It has been divided into several sections, and this section comprises 15 questions that include entrepreneurial attitudes and perceptions, entrepreneurial motivation and aspiration, entrepreneurial capacity and the effect of both on economic growth. The answers provide insights into the importance of IT business, as well as GDP growth, especially in the context of economies that may show fluctuations.

The questionnaire was distributed online, using Google forms, to young people, 11th and 12th grade students from 40 high schools in Romania. I received a questionnaire response from 20 high schools, respectively from 159 young people. All 159 questionnaires were completed correctly, these being the object of statistical analysis.

The population that is the subject of the survey, is made up of a sample of 159 young people, 11th and 12th grade students from 20 technological high schools in Romania. The young people are between the ages of 16-20, and in terms of sex, the respondents are both female and male. Of the young respondents, $113(71 \%)$ are female and $46(29 \%)$ are male. The respondents are young people who have taken entrepreneurship courses during high school, because the high schools in the country have in their curriculum modules on entrepreneurship, and for the statistical extraction, the Microsoft Excel program was used.

The questionnaire helped us determine the importance of IT enterprises in young people and to analyze the attitudes, perceptions, aspirations, level of motivation and ability of young people to take entrepreneurial initiatives in relation to IT and innovation based businesses.

In the study we also used the economic growth framework of the GEM, which means that social, cultural and political affiliations influence entrepreneurial initiatives among young people and these factors lead to the exploitation of entrepreneurial opportunities.

The diagram in figure 3 shows that the respondents are aware that it is not very easy to start a business (19\%) and they are also afraid of failing (15\%), but most (34\%) have intentions to start a business and $(27 \%)$ consider that they have acquired the skills and knowledge to be a good manager.

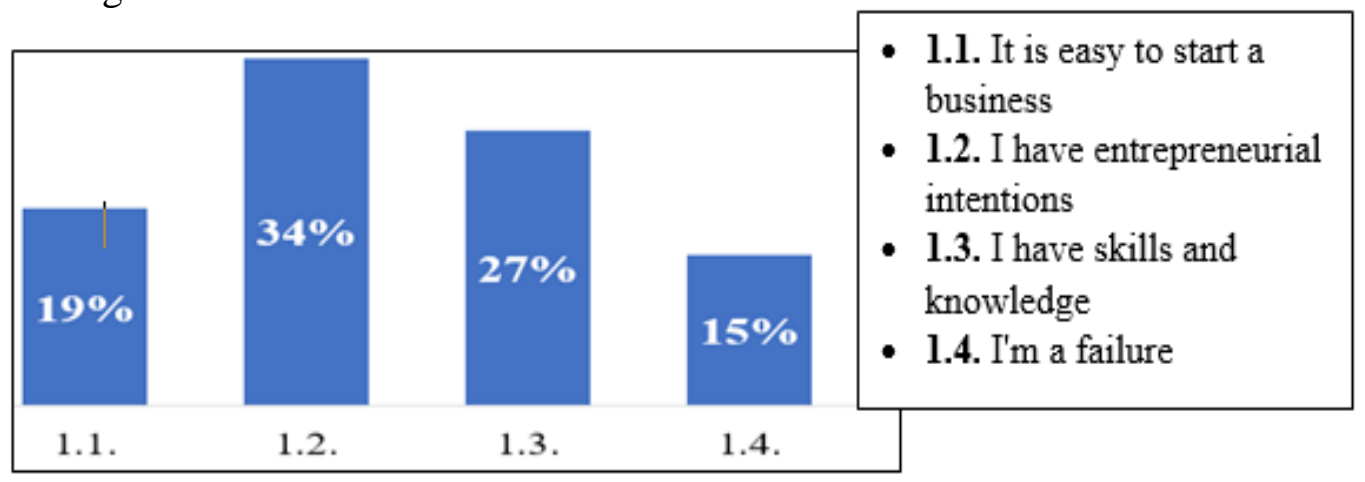

Figure 3. Indicators on attitudes and perceptions

The set of questions shown in figure 4, shows the motivation of the respondents for the new start-ups. The respondents are extremely motivated to establish their new businesses, despite the fact that they are in their penultimate or last year of study. Regarding the importance of IT related businesses, it is noted that $23 \%$ of the respondents want to set up an IT business, representing more than half of those who want to set up a business. 
www.conferenceie.ase.ro

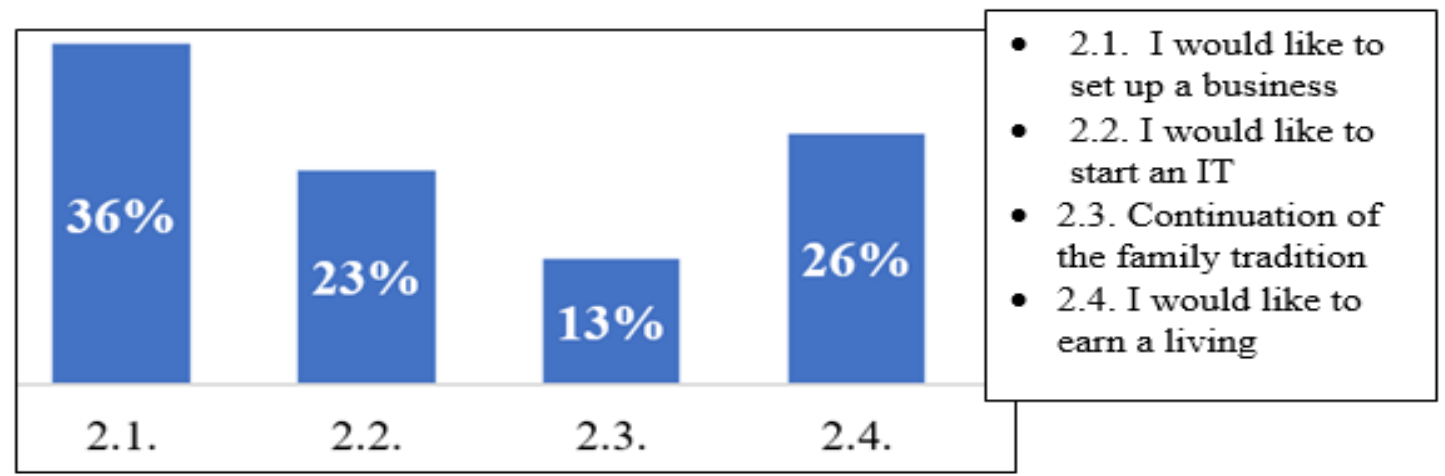

Figure 4. Indicator on motives and aspirations

From the answers given to the questions that concern the opinion of the respondents about entrepreneurship and the IT field, the results represented in figure 5, show that entrepreneurial ideas, more specifically IT projects are a necessity for economic growth. Within the study, the gender mix of respondents is observed.

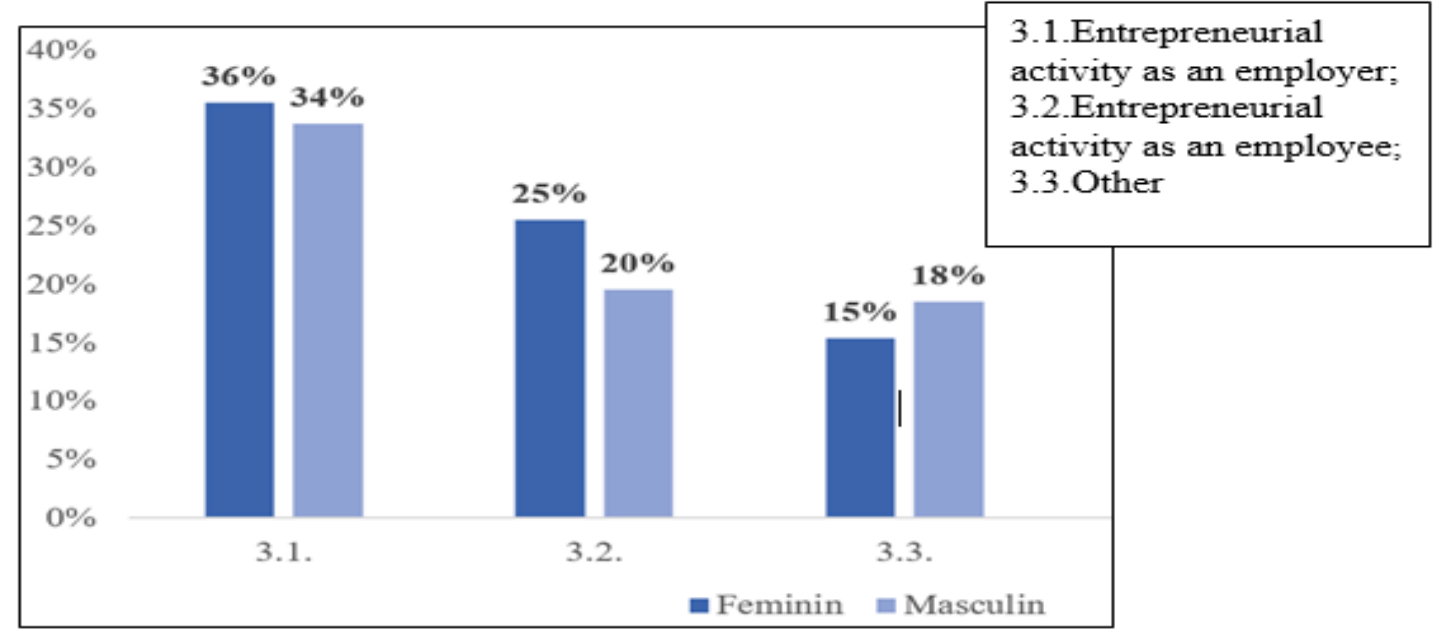

Figure 5. Entrepreneurial activity regarding the gender mix

Women's interest in entrepreneurial initiatives could be beneficial for economies where women do not yet have professional missions. Their role in IT-oriented businesses can pave the way to start new businesses by maintaining a perfect balance between family and professional life. Based on all the indicators described, the conditions of the entrepreneurial framework of a country can be outlined. Also, GEM achieved the economic profiles of the 50 economies that participated in the 2019 GEM adult population study, including 11 from the Middle East and Africa, 8 (eight) from Asia and the Pacific, 8 (eight) from Latin America and the Caribbean. and 23 from Europe and North America. Of these economies 5 (five) are classified as low income level, 12 as medium income and the rest with high income. [5]

The results reached, following the study carried out in the 20 technological high schools in Romania, can be considered fundamental to recommend the introduction into the school curriculum of entrepreneurship or entrepreneurial education. This practice is common in European countries and should be adopted by Romania as well. The country's decision-makers should also develop policies for encouraging entrepreneurship, both for women, the media and civil society, as well as for the IT field. 
www.conferenceie.ase.ro

\section{Conclusions}

Internationally, entrepreneurship is recognized as a generator of prosperity in society and a decisive element for economic growth and job creation and supporting entrepreneurship has become a priority in recent years, being considered a solution for exiting the crisis and stopping the worrying unemployment rate.

It follows from this research that young people are certainly concerned about developing business, they have a huge motivation to start their own projects and a good perspective on entrepreneurial businesses that are an effective tool to grow their income. Their motivation is high and they are also impressed by the recent IT giants, thus considering that the IT companies offer economic momentum either from the position of employer, versus employee. This leads us to the conclusion that establishing an IT business based on computer-aided systems and methodologies can not only bring innovation, but also guarantee more returns, in contrast to fewer investments that would otherwise have been required in businesses. traditional of the same level. Therefore, the time required for investors to bring the sector of small and mediumsized enterprises in perfect alignment with IT based business. As banks' aid is important for financing start-ups, it is mandatory for them to make policies and procedures that allow potential businesses to agree with financing options.

The study shows that there is a great tendency for start-ups to cope with the worsening economic scenarios, especially when there is a strong interest and motivation among young people to start IT-based businesses, as they represent the future of any country.

It can be concluded that the measures and actions of entrepreneurial education in the technological high schools in Romania are fragmented and vary in quality, coexisting both successful initiatives of some nuclei of excellence, as well as many projects without a relevant theoretical or practical level. Entrepreneurship should be promoted as an alternative to the classical professional career and the Romanian state should promote entrepreneurship in school, early entrepreneurial education being vital to the formation of entrepreneurial skills and behavior in Romanian society. The systemic approach is required by integrating into an "ecosystem" of entrepreneurial education in all forms, starting with the compulsory program in the national education system, continuing with the improvement of the training offer at university level and the continuous vocational training. Romania should develop a national strategy for entrepreneurship education based on the success models of other European states.

\section{References}

[1] E. Edelhauser, A. Ionică and C. Lupu, "Enterprise Resource Planning and Business Intelligence, Advanced Management Methods for Romanian Companies", in Proc. The 1st Management Conference: Twenty Years After, How Management Theory Works,Technical University of Cluj Napoca, Todesco Publishing House, 2010, pp. 63-72. Available: http://conference2010.rmee.org/List\%20of\%20ACCEPTED\%20papers.pdf

[2] C. Román, E. Congregado and J.M. Millán, Start-up incentives: Entrepreneurship policy or active labour market programme?, Journal of Business Venturing, 28(1), 2013, pp. 151175.

[3] M. Bogdanowicz (2015), Digital Entrepreneurship Barriers and Drivers. The need for a specific measurement framework; Institute for Prospective Technological Studies; JRC Technical Report. Available: https://ec.europa.eu/jrc/en

[4] N. Bosma, PhD, Utrecht University, Netherlands Professor Stephen Hill, DSc, Lead Author A.I. Somers, PhD, GEM Executive Director Professor D. Kelley, PhD, Babson College, United States Professor Jonathan Levie, PhD, National University of Ireland, Galway Anna Tarnawa, Polish Agency for Enterprise Development (2019), Global Entrepreneurship Monitor 2019/2020 Global Report. Available: https://www.gemconsortium.org/report 
www.conferenceie.ase.ro

[5] E.I. Popa, A. Furdui, E. Edelhauser, "Considerations on management for technological entrepreneurship”, International Conference on Manufacturing Science and Education, MSE Sibiu, 2019.

[6]Internet:http://www.fntm.ro/global-entrepreneurship-monitor--gem--2015-antreprenoriatul-castiga-teren-in-intreaga-lume-3668.html 